\title{
The Declining Presence of Family Physicians in Hospital-Based Care
}

\author{
Anuradha Jetty, MPH, Yalda Jabbarpour, MD, Stephen Petterson, PhD, \\ Aimee Eden, PhD, MPH, and Andrew Bazemore, MD, MPH
}

Despite training to provide care across the continuum of health delivery settings, the proportion of family physicians (FPs) reporting inpatient care has decreased by $26 \%$ between 2013 and 2017, leaving approximately 1 in 4 of FPs practicing hospital medicine in 2017. Policy makers, payers, and leaders in medical education should closely track the impact of these trends, given previous evidence associating better cost and utilization outcomes with broader scope of practice. (J Am Board Fam Med 2019;32: 771-772.)

Keywords: Continuity of Patient Care, Family Physicians, Health Policy, Hospital Medicine, Inpatients, Leadership, Medical Education, Pay for Performance, Residency

Comprehensiveness is one of the Starfield's core tenets of primary care. Patients of family physicians (FPs) with a broader scope of practice have been shown to have lower overall health care spending. ${ }^{1}$ Given the proportion of FPs providing care across a range of services and settings continues to narrow, ${ }^{2}$ this brief explores the trends in provision of hospital-based care among FPs.

We used data from the 2013 to 2017 American Board of Family Medicine Certification Examination application questionnaire to examine trends in hospital care for the most recent years available. This survey included a series of questions about the provision of specific services. We performed descriptive analyses on the sample of FPs who provide direct patient care. Among 46,762 respondents across 5 years, the share of FPs reporting hospital

This article was externally peer reviewed.

Submitted 26 April 2019; revised 24 June 2019; accepted 25 June 2019.

From the Robert Graham Center, Washington, DC (AJ, YJ, SP, AB); The American Board of Family Medicine, Lexington, $\mathrm{KY}$ (AE).

Funding: none.

Conflict of interest: $\mathrm{AE}$ is an employee of the American Board of Family Medicine.

Author Contributions: All authors made a substantial contribution to the research and in writing the policy brief, and are responsible for its content jointly and individually.

Corresponding author: Anuradha Jetty, MPH, Robert Graham Center, 1133 Connecticut Ave, NW \#1100, Washington, DC 20036 (E-mail: ajetty@aafp.org). care decreased from $34.1 \%$ in 2013 to $25.2 \%$ in 2017 (see Table 1).

As observed in other domains (prenatal care, home visits, nursing home care, and obstetric care), ${ }^{2}$ this study adds to the evidence demonstrating contracting scope of practice among FPs. ${ }^{3}$ A decade ago, family medicine residency directors openly debated the continued inclusion of hospital medicine in family medicine residency training. ${ }^{4}$ Theoretically, continuity of care across settings translates to better health outcomes for patients. Yet, the recent evidence on the benefits of continuity by a provider ${ }^{5}$ and comprehensiveness of services ${ }^{1}$ have not focused on the effects of following one's patients between settings. As the proportion of family physicians providing inpatient and outpatient services shrinks, we need better research on the impact that practicing across settings may have on patients and health systems.

To see this article online, please go to: http://jabfm.org/content/ 32/6/771.full.

\section{References}

1. Bazemore A, Petterson S, Peterson LE, Phillips RL. More comprehensive care among family physicians is associated with lower costs and fewer hospitalizations. Ann Fam Med 2015;13:206-213.

2. Coutinho AJ, Cochrane A, Stelter K, Phillips RL Jr, Peterson LE. Comparison of intended scope of prac- 
Table 1. Family Physicians' Self-Reported Provision of Inpatient Care (2013 to 2017)

\begin{tabular}{lrrrrr}
\hline Year of Survey & 2013 & 2014 & 2015 & 2016 & $2017^{*}$ \\
Total FPs surveyed (N) & 10,673 & 10,064 & 8,464 & 8,886 & 8,675 \\
FPs reporting inpatient care (n) & 3,637 & 3,386 & 2,551 & 2,551 & 2,182 \\
Share of FPs reporting inpatient care (\%) & 34.1 & 33.6 & 30.9 & 28.7 & 25.2 \\
\hline
\end{tabular}

ABFM, American Board of Family Medicine; FP, family physician.

Source: ABFM Demographic Survey (2013 to 2017).

Sample restricted to FPs in direct patient care.

*In 2017, ABFM Diplomates were asked whether they provided adult inpatient care instead of inpatient care in the previous years.

tice for family medicine residents with reported scope of practice among practicing family physicians. JAMA 2015;314:2364-2372.

3. Carek PJ. Potentially alarming trends in the scope of practice for family physicians. J Am Board Fam Med 2018;31:178-180.

4. Association of Family Medicine Residency Directors. Is the family physician in or out of hospital medicine? A discussion of pertinent perspectives to consider as we address inpatient curricular review. Ann Fam Med 2009;7:471-472.

5. Bazemore A, Petterson S, Peterson LE, Bruno R, Chung Y, Phillips RL. Higher primary care physician continuity is associated with lower costs and hospitalizations. Ann Fam Med 2018;16:492497. 